\title{
Uma ferramenta de apoio ao ensino e aprendizagem de regra de três
}

\author{
A tool to support the teaching and learning of the rule of three \\ Robson Damião da Rocha Raimundo*, Marco Antônio Pereira Araújo \\ Resumo
}

Como citar esse artigo. Raimundo RDR, Araújo MAP. Uma ferramenta de apoio ao ensino e aprendizagem de regra de três. Revista Eletrônica Teccen. 2016 Jan./Jun.; 09 (1): 09-19.

\begin{abstract}
Este trabalho objetivou o desenvolvimento de uma ferramenta de apoio ao ensino e aprendizagem de Regra de Três. Seu desenvolvimento se baseou na hipótese de que esta ferramenta poderia contribuir para a diminuição dos efeitos de erros cometidos por profissionais da Saúde ao administrar e prescrever medicamentos. Esta ferramenta é parte do produto desenvolvido para um projeto do Mestrado Profissional em Educação Matemática da Universidade Severino Sombra. A ferramenta foi submetida a uma avaliação e análise estatística dos resultados, cujo objetivo foi o de observar sua eficácia. Foi desenvolvido um instrumento de avaliação com oito questões retiradas de concursos públicos e processos seletivos para enfermeiros ou técnicos em enfermagem e do ENADE dos anos de 2007, 2010 e 2013. A constatação da eficácia da ferramenta se deu mediante a utilização do teste T de Student pareado para comparar as médias de duas amostras dependentes provindas da aplicação deste instrumento a alunos concluintes de um curso superior de enfermagem. Estas amostras foram resultantes da aplicação do instrumento de avaliação anteriormente e posteriormente à utilização da ferramenta. Demonstrou-se, assim, que a ferramenta contribuiu positivamente no aprendizado.
\end{abstract}

Palavras-Chave: Regra de Três; Enfermagem; Cálculo de Dosagens.
Trabalhar com números nem sempre é agradável para alguns, principalmente para aqueles que enfrentaram dificuldades com a Matemática durante o período escolar (Silveira, 2000). Em se tratando da Matemática aplicada à enfermagem, este problema toma proporções ainda maiores, visto o número de possíveis consequências derivadas de erros no cálculo de dosagens, diluição e gotejamento de medicamentos, que vão desde reações alérgicas até a morte (Carvalho \& Cassiani, 2002).

A administração ou prescrição de medicamentos é uma das atividades mais sérias e de maior responsabilidade da enfermagem e, para a sua execução, é necessária a aplicação de vários princípios que fundamentam a ação do enfermeiro, de forma a prover a segurança necessária (Carvalho et al., 1999).

No contexto do ensino na área da Saúde, é grande a responsabilidade do professor de Matemática, porque é através do domínio de cálculos matemáticos básicos que o futuro profissional resolverá problemas que envolvem a administração de medicamentos. Estes profissionais têm, muitas vezes, a vida em suas mãos e devem desempenhar seu trabalho com responsabilidade e competência (Klug \& Ramos, 2013).

Enunciando os conteúdos de Matemática, conhecimentos são manifestados na prática de técnicos em enfermagem e aqueles que apresentam um maior grau de dificuldade são os relacionados às operações que necessitam de divisão, como porcentagem e números fracionários. Estas operações são muito utilizadas em cálculos de gotejamento de soro, de

Afiliação dos autores: Universidade Severino Sombra, Vassouras-RJ, Brasil.

* Endereço para correspondência: Universidade Severino Sombra, Av. Exped. Oswaldo de Almeida Ramos, 280 - Centro - Vassouras, RJ - CEP $27700-000$.

E-mail: robsonndarocha@gmail.com 
gotas em mililitros por hora, preparos e diluição de medicamentos, alterações nas concentrações de drogas e preparo de soluções. Algumas prescrições, baseadas em Unidades Internacionais de Medidas, nem sempre coincidem com a apresentação da droga em si, pois, existem muitas variações nas apresentações, conforme o fabricante. Outras vezes, a forma de apresentação diverge da prescrita, necessitando de conversão de unidades de medida, bem como diluição ou adequação na concentração e rediluição dos medicamentos prescritos pelos médicos (Klug \& Ramos, 2013).

A dificuldade encontrada por alunos de enfermagem em Matemática exige, certamente, um "remédio". Acredita-se que este "remédio" já está sendo preparado por algum "alquimista" da educação. Talvez mudando o enfoque do ensino tradicional, buscando novas ideias, ajudando o aluno a descobrir, construir e pensar, ao invés de oferecê-lo "tudo pronto" (Klug \& Ramos, 2013).

Nos processos educacionais formais, a operação de Regra de Três é apresentada ao aluno como possibilidade de solução de problemas de proporcionalidade. É apresentada como uma fórmula pronta, de maneira que o aluno não the atribui significado, ficando os procedimentos matemáticos destituídos de sentido (Klug \& Ramos, 2013).

Quando se faz uso do computador para a construção de conhecimento, o computador passa a ser uma máquina a ser ensinada, propiciando condições para o usuário descrever a resolução de problemas, usando linguagens de programação, refletir sobre os resultados obtidos e depurar suas ideias por intermédio da busca de novos conteúdos e novas estratégias. Neste caso, os softwares utilizados podem ser os softwares abertos de uso geral, como as linguagens de programação, sistemas de autoria de multimídia, processadores de texto ou softwares para criação e manutenção de bancos de dados. Em todos estes casos, o usuário utiliza o computador para resolver problemas ou realizar tarefas como navegar na Web, desenhar, escrever,calcular, entre outras. A construção do conhecimento advém do fato de o usuário ter de buscar novos conteúdos e estratégias para incrementar o nível de conhecimento que já dispõe sobre o assunto que está sendo tratado via computador (Valente, 2008).

Por outro lado, o uso do computador na criação de ambientes de aprendizagem que enfatizam a construção do conhecimento apresenta enormes desafios. Primeiro, implica em entender o computador como uma nova maneira de representar o conhecimento, provocando um redimensionamento dos conceitos já conhecidos e possibilitando a busca e compreensão de novas ideias e valores. Usá-lo com esta finalidade requer a análise cuidadosa do que significa ensinar e aprender, bem como demanda rever o papel do professor neste contexto (Valente, 2008).
Com o intuito de abordar, efetivamente, o problema encontrado neste cenário, uma ferramenta para apoiar o ensino e aprendizagem de Regra de Três foi desenvolvida.

Este artigo está organizado da seguinte maneira: a seção dois apresenta a metodologia utilizada na implementação da ferramenta, a seção três aborda a construção da ferramenta, a seção quatro apresenta o estudo de caso realizado para verificar a eficácia da ferramenta, a seção cinco conclui o artigo com as contribuições, dificuldades e trabalhos futuros.

\section{Metodologia}

A metodologia utilizada na realização deste trabalho consiste na seguinte sequência:

1. Realização de um levantamento da real situação do ambiente o qual a ferramenta se propõe a auxiliar de forma que a mesma seja adequada;

2. Definição dos requisitos funcionais e não funcionais, dos casos de uso e de toda a documentação prévia à implementação da ferramenta;

3. Implementação da ferramenta;

4. Realização dos devidos testes na ferramenta;

5. Implementação das devidas melhorias;

6. Avaliação da ferramenta e análise estatística dos resultados.

$\mathrm{Na}$ etapa 1 foram realizadas diversas pesquisas bibliográficas e de campo acerca do assunto a ser abordado. Além disto, diversos profissionais da área de Saúde foram ouvidos através de diálogos informais, objetivando maior precisão na abordagem do problema.

$\mathrm{Na}$ etapa 2, todo o material reunido na etapa 1 foi compilado em um documento de especificação de requisitos, um diagrama de Casos de Uso e um diagrama de classes que estão dentre os documentos técnicos mais utilizados para a idealização de um software.

$\mathrm{Na}$ etapa 3, os respectivos documentos técnicos foram utilizados como base para o desenvolvimento da ferramenta. Isto inclui (i) a definição da interface de usuário, através da linguagem de marcação de hipertexto e das folhas de estilo; (ii) a definição do modelo de dados e (iii) da lógica de negócio, através das linguagens de programação e de script.

$\mathrm{Na}$ etapa 4, a ferramenta foi submetida a testes unitários automatizados e a testes realizados por voluntários diversos, tais como, profissionais da área de Tecnologia da Informação, da área de Saúde e de demais áreas de atuação.

$\mathrm{Na}$ etapa 5, todas as colocações feitas pelos voluntários supracitados foram devidamente implementadas na ferramenta.

$\mathrm{Na}$ etapa 6, a ferramenta foi submetida a um teste mais rigoroso no qual foram coletadas informações a 
serem devidamente analisadas para que a eficácia da ferramenta fosse corroborada ou não. Esta etapa será melhor detalhada na seção quatro deste trabalho.

\section{Construção da ferramenta}

Diante da abordagem idealizada para a ferramenta, fez-se necessário que a mesma fosse eficaz no que tange o cálculo, e lúdica no que tange o ensino e o aprendizado. Desta forma, a solução para um problema seria não só encontrada, como entendida. E, uma vez entendida a solução para um problema, este poderá ser resolvido em suas mais diversas formas, como comumente se vê em Matemática (Fiorentini, 1995).

A ferramenta foi desenvolvida para elucidar cada particularidade da operação de Regra de Três fazendo uso de animações. Com isto, deixa-se claro para o usuário o que ocorre com a operação a cada interação realizada.A mesma pode ser acessada através do link: www.calculotemremedio.com.br/RegraDeTres. Sua interface é ilustrada na Figura 1.

Como pode-se perceber, a interface da ferramenta é baseada em painéis que agrupam determinados componentes que, juntos, fazem referência às partes de uma operação de Regra de Três. A seguir, uma breve descrição.

- Os painéis superiores centrais contêm os algarismos e símbolos utilizados para compor os valores dos campos da operação;

- O painel esquerdo contém a proporção da operação. Esta é composta por campos a serem preenchidos e uma incógnita. Acima de cada razão pode-se ver uma pequena lista contendo grandezas prédefinidas;

- Logo acima deste mesmo painel encontra-se um símbolo de maximização que, quando clicado, expande um painel idêntico ao inferior, só que com entrada via teclado;

- Ao meio, percebe-se um sinal indicativo de implicação. Quando clicado, a proporção é transformada em razão e os respectivos valores flutuam de um painel ao outro;

- O painel direito contém a razão da operação;

- Acima deste painel, encontra-se mais um símbolo de maximização. Este expande um pequeno painel que contém os artefatos necessários para a correção de um resultado obtido manualmente;

- Logo abaixo, há os botões de cálculo e reinício da aplicação, respectivamente;

- No canto inferior direito há um pequeno painel que exibe as alterações de valores em tempo real. Seu cunho é, estritamente, informativo.

\section{Tecnologias}

Para o desenvolvimento da ferramenta, foram utilizadas diversas tecnologias de desenvolvimento Web. Estas foram escolhidas visando o maior aproveitamento do tempo disponível para desenvolvimento, assim como uma maior abstração de detalhes que não fossem os da lógica da própria ferramenta. As mesmas são descritas a seguir.

Java

Java é uma linguagem de programação orientada a objetos, desenvolvida na década de 90 pela empresa SunMicrosystems. Diferentemente das linguagens convencionais, que são compiladas para código nativo, a linguagem Java é compilada para bytecodes que são executados por uma máquina virtual. A linguagem de programação Java é a linguagem convencional da

\section{9}

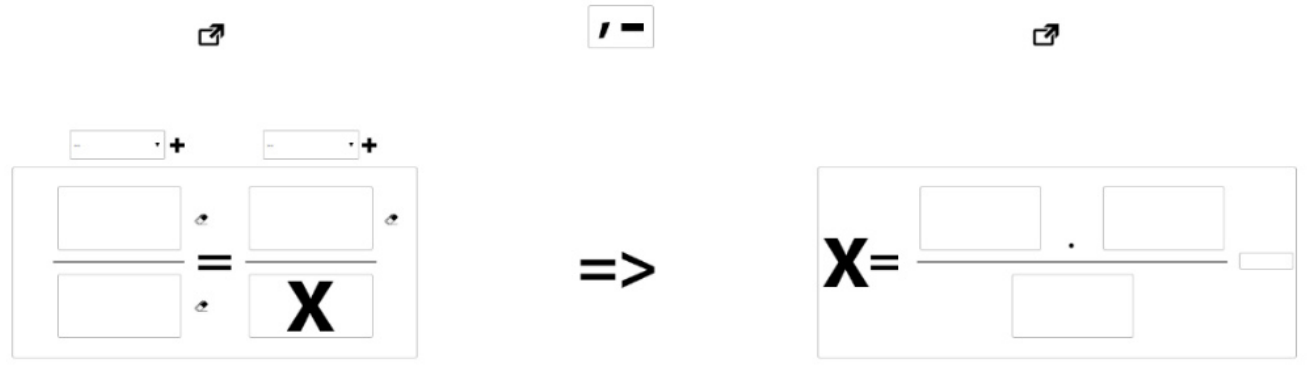

Figura 1. Interface da Ferramenta de Regra de Três. Fonte: próprios autores. 
Plataforma Java, mas não sua única linguagem (Deitel\& Deitel, 2010).

A linguagem Java foi escolhida como sendo a mais adequada para o desenvolvimento da ferramenta pela sua portabilidade, robustez e pelo grande número de bibliotecas úteis que possui. Desta maneira, muito do que não concerne à lógica da aplicação pôde ser deixado de lado graças ao suporte oferecido por esta linguagem de programação. Sem levar em consideração o número de frameworks de desenvolvimento que a mesma possui e de outras tecnologias com as quais é facilmente utilizada.

Java foi utilizada nas camadas Model e Controller do padrão MVC (Model-View-Controller), que foi o padrão utilizado para a concepção da aplicação. Nelas, definiram-se o modelo de dados e os diversos cálculos e ademais concernentes ao que a mesma se propõe a realizar, chamados de lógica de negócio.

\section{JavaServer Faces (JSF)}

JavaServerFaces é um framework MVC baseado em Java para a construção de interfaces de usuário baseadas em componentes para aplicações Web. Possui um modelo de programação dirigido a eventos, abstraindo os detalhes da manipulação dos eventos e organização dos componentes, permitindo que o programador se concentre na lógica da aplicação (Geary \& Horstmann, 2010).

JavaServer Faces foi oframework Web escolhido por possuir uma grande gama de componentes úteis para a concepção da ferramenta, aumentando a produtividade em grandes proporções.

A ferramenta está em conformidade com os preceitos do desenvolvimento em JavaServer Faces. Desta forma, o modelo de dados e a lógica de negócio foram desenvolvidos em Java, e o visual (View) foi desenvolvido em XHTML (eXtended HypertextMarkup Language). Vale ressaltar que, ao utilizar o framework JavaServer Faces, utiliza-se as tecnologias de desenvolvimento Web: HTML5 (Hypertext Markup Language, version 5), CSS3 (Cascading Style Sheets, version 3) e JavaScript (jQuery e AJAX (Asynchronous JavaScript and XML)). Estas são utilizadas por meio de tags próprias do framework.

\section{PrimeFaces}

PrimeFaces é uma suíte de componentes de código aberto para aplicações Web baseadas em JavaServerFaces. Possui mais de 100 componentes, framework AJAX, kit de interface de usuário para dispositivos móveis, framework Push, validação no lado do cliente e motor de temas (Varaksin, 2013).

A utilização desta suíte se deu mediante a necessidade de uma maior gama de componentes para figurar na ferramenta, assim como a necessidade de uma maior extensão das possibilidades de utilização do AJAX. A maioria dos componentes presentes na ferramenta é de origem desta suíte, com exceção dos componentes mais básicos, como caixas de texto e botões.

O modo de utilização da suíte é o mesmo do JavaServer Faces. Todos os componentes são inseridos em forma de tags que, por sua vez, trazem consigo toda a tecnologia necessária para a realização da tarefa para a qual foram desenvolvidas.

\section{jQuery}

jQuery é uma biblioteca JavaScript de código aberto desenvolvida para simplificar os scripts que interagem com o HTML, sendo uma das mais populares bibliotecas JavaScript (Franklin, 2013).

Esta foi utilizada devido ao enorme aumento de produtividade que proporciona, além de trazer à tona diversas funções prontas que facilitam muito o desenvolvimento Web.

Não há alterações muito drásticas quanto à sintaxe em comparação com JavaScript. Sua utilização depende do anexo da biblioteca ao arquivo em desenvolvimento, somente. Uma vez feito isto, basta escrever o código normalmente dentro das especificações da biblioteca.

Foi utilizada em toda a parte interativa da ferramenta que já não houvesse um componente do framework Web JavaServerFaces ou da suíte de componentes PrimeFaces que fosse apto a realizar determinada tarefa. Foi desenvolvido um script à parte e este anexado ao arquivo da página principal da ferramenta para que fosse executado logo após o carregamento da mesma.

\section{NetBeans IDE (Integrated Development Environment)}

NetBeans IDE é um ambiente de desenvolvimento integrado gratuito e de código aberto para desenvolvedores de software nas linguagens Java, $C, C++$, PHP (PHP: HypertextPreprocessor), Groovy, Ruby, entre outras. O IDE pode ser executado nas plataformas Windows, Linux, Solaris e MacOS. Oferece aos desenvolvedores as ferramentas necessárias para criar aplicativos profissionais de desktop, empresariais, Web e móveis multiplataformas (Dantas, 2011).

Este IDE foi escolhido para o desenvolvimento por simplificar o mesmo, aumentar a produtividade e, principalmente, por estar em perfeita sintonia com as tecnologias supracitadas.

Foi utilizado em todas as etapas do desenvolvimento da ferramenta, pois, possui um editor robusto capaz de trabalhar com linguagens de programação, de script e de marcação, oferecendo todos os recursos necessários ao desenvolvimento deste trabalho. 


\section{Documentação}

A seguir, são detalhados alguns componentes básicos da documentação da ferramenta.

\section{Requisitos}

São descritos a seguir os requisitos para o desenvolvimento da Ferramenta de Regra de Três.

\section{Requisitos funcionais}

- Definir uma proporção;

- Transformar a proporção em razão;

- Calcular o resultado;

- Corrigir o resultado.

Requisitos não funcionais

- Suportar o processamento multiusuário;

- Animar os valores em resposta à interação do usuário.

\section{Diagramas}

Nas Figuras 2 e 3 podem-se observar dois dos principais diagramas da UML (Unified Modeling Language). Estes representam as possíveis interações com a ferramenta, assim como a estruturação da mesma, respectivamente.

$\mathrm{Na}$ Figura 2 temos o diagrama de Casos de
Uso, que representa como o usuário interage com a ferramenta e quais são as respectivas operações realizadas subsequentemente. $\mathrm{O}$ usuário pode realizar três interações principais: (i) "Montar a Proporção", onde o usuário insere os valores e grandezas desejados e posiciona a incógnita; (ii) "Transformar a Proporção em Razão", onde o usuário clica sobre o símbolo da implicação; e (iii) "Calcular o Resultado", onde o usuário clica sobre o respectivo botão e a ferramenta exibe o resultado. Em um fluxo alternativo, o usuário pode optar por realizar as ações i e ii e, ao invés de solicitar o cálculo automático, realizar o mesmo manualmente. Ao final, pode inserir sua resposta no devido campo de correção e solicitar a correção automática, interagindo, assim, com o caso de uso "Corrigir o Resultado".

$\mathrm{Na}$ Figura 3 temos o diagrama de classes, que define a estrutura da ferramenta. Neste encontramse as classes e seus respectivos atributos e métodos necessários para a concepção da ferramenta. Esta estrutura foi idealizada com o intuito de reduzir, ao máximo, o acoplamento entre as partes operantes (classes), aumentando a escalabilidade (capacidade de ser expandida) e manutenibilidade (facilidade de manutenção).

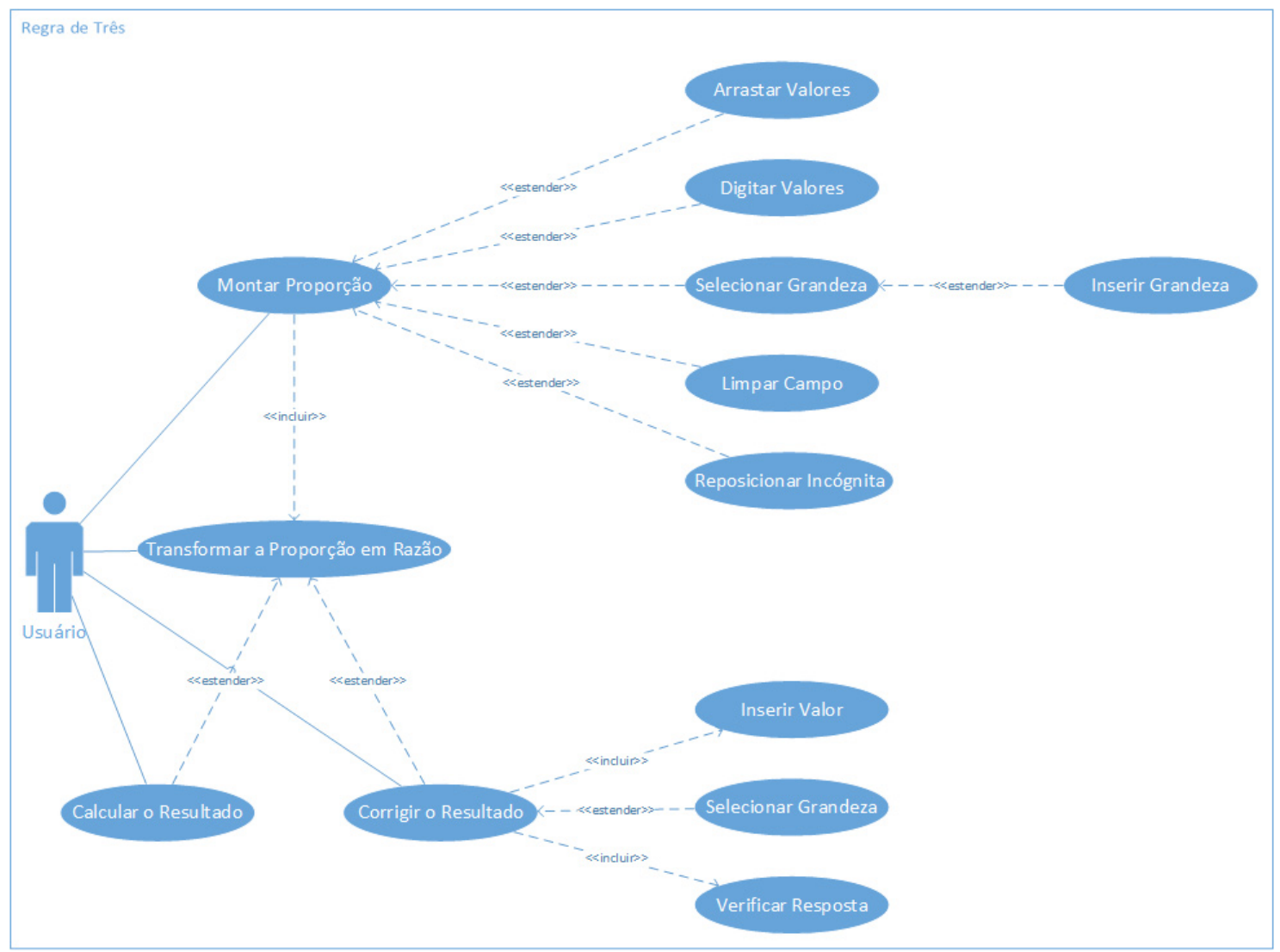

Figura 2. Diagrama de Casos de Uso.

Fonte: próprios autores. 


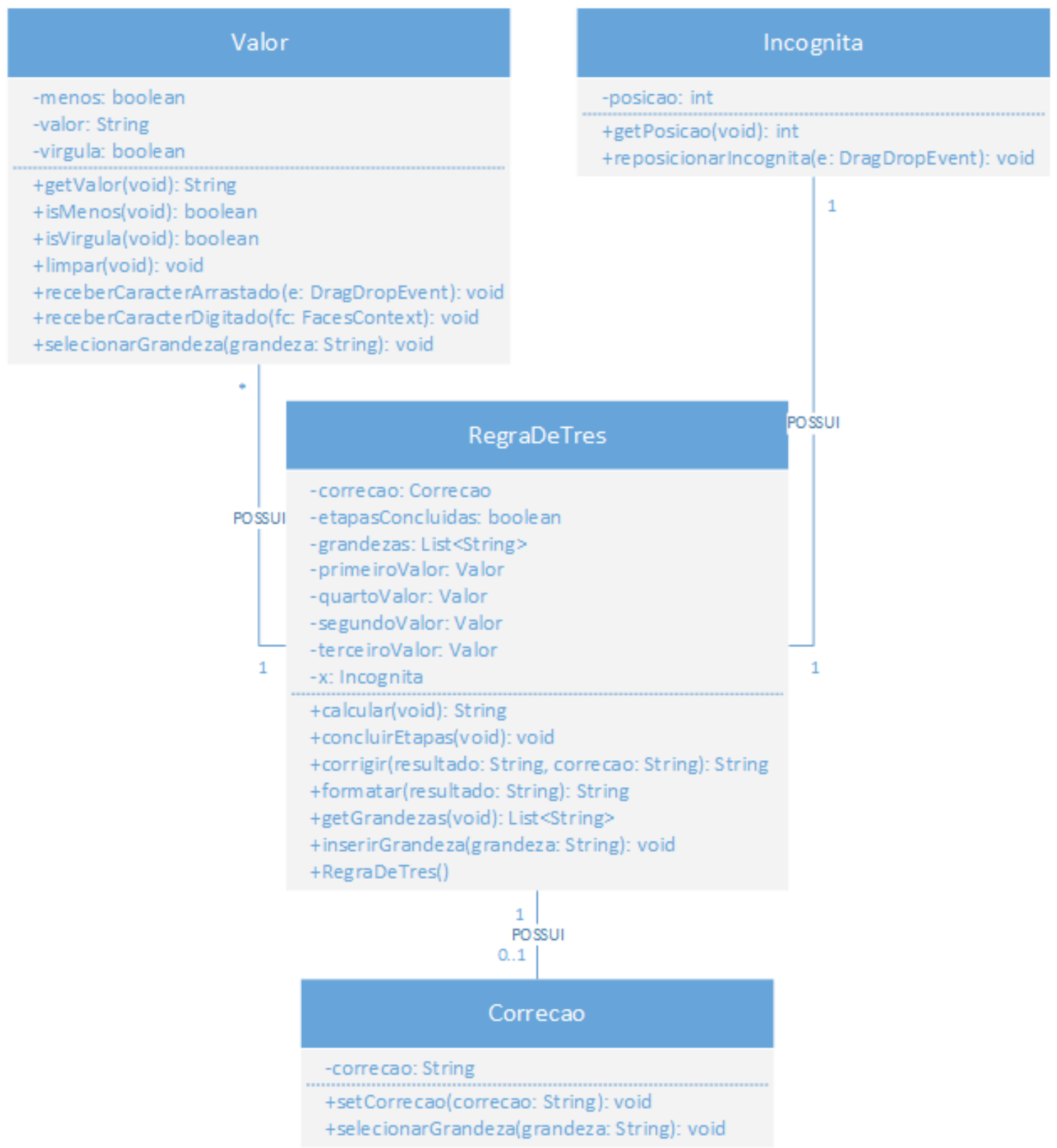

Figura 3. Diagrama de classes.

Fonte: Próprios autores.

\section{Estudo de caso}

Com o intuito de corroborar o resultado obtido por demais pesquisas acerca deste mesmo assunto, tanto mencionadas em Cunha (2014), como referenciadas neste trabalho, assim como afim de avaliação da Ferramenta de Regra de Três, este estudo de caso foi desenvolvido.

Os dados foram coletados através de um instrumento de avaliação contendo oito questões objetivas envolvendo os saberes necessários ao cálculo de dosagens, diluição e gotejamento de medicamentos. As questões foram extraídas de processos ou concursos públicos para enfermeiros ou técnicos em enfermagem, assim como do ENADE dos anos de 2007, 2010 e 2013. O critério de seleção das questões foi: (i) questões que envolvessem a aplicação de conhecimentos matemáticos, (ii) questões que envolvessem o cálculo de dosagens, diluição e gotejamento de medicamentos e (iii) questões que envolvessem grandezas.

O instrumento de avaliação foi aplicado a 20 alunos concluintes do curso de enfermagem da Universidade Castelo Branco - Campus Realengo - RJ, pois, já haviam cursado as disciplinas de Semiologia I e II, onde são abordados os conteúdos relacionados ao cálculo de dosagens, diluição e gotejamento de medicamentos.

Os alunos foram informados sobre o estudo de caso, com o qual todos aderiram voluntariamente. Receberam,juntamente com oinstrumento de avaliação, um Termo de Consentimento Livre e Esclarecido, pelo qual concordaram em participar do estudo, mediante assinatura. Não foi permitido esclarecer dúvidas quanto às questões, assim como também foi vetado o 
uso de calculadora, livros ou qualquer outro recurso de consulta.

A aplicação deste instrumento de avaliação, no primeiro momento, teve como finalidade verificar o conhecimento prévio dos alunos com relação ao cálculo de dosagens, diluição e gotejamento de medicamentos. Esta etapa foi chamada de préteste. A segunda etapa, chamada de pós-teste, foi a aplicação deste mesmo instrumento de avaliação após os candidatos terem usado e se familiarizado com a Ferramenta de Regra de Três. Deste modo, através dos resultados, pôde-se se verificar o impacto do uso da ferramenta através da análise estatística realizada com os resultados obtidos. Os detalhes desta análise são apresentados a seguir.

Segundo relatos da professora que ministra as disciplinas de Semiologia I e II na Universidade Castelo Branco - Campus Realengo - RJ, houve acessos por parte de seus alunos por duas semanas consecutivas, totalizando seis horas de utilização da Ferramenta de Regra de Três. Havendo, ainda, relatos de alunos que o fizeram fora do ambiente acadêmico.

Com base nos resultados obtidos anterior e posteriormente à utilização da Ferramenta de Regra de Três, foi compilada uma tabela demonstrativa cujos valores são os obtidos nas aplicações do instrumento de avaliação, como pode-se ver na Tabela 1 .

$\mathrm{Na}$ Tabela 1 consegue-se perceber, claramente, que alguns dos voluntários obtiveram melhora em seus resultados após o uso da ferramenta, porém, para corroborar, conclusivamente, esta premissa, a análise a seguir foi realizada com base no estudo estatístico presente em Cunha (2014).

\section{Análise das variáveis pré-teste e pós-teste}

Estas variáveis representam as notas totais obtidas pelos estudantes na realização da atividade proposta anterior e posteriormente à utilização da Ferramenta de Regra de Três.

\section{Teste de hipótese}

Há diferença entre as notas dos voluntários antes da utilização da ferramenta (pré-teste) e após a utilização da ferramenta (pós-teste)?

- H0: as notas antes do uso da ferramenta são iguais às notas após a utilização da ferramenta;

- H1: as notas são diferentes.

Nível de significância $\alpha=5 \%$.
Tabela 1. Notas no pré-teste e no pós-teste.

\begin{tabular}{ccc}
\hline \multirow{2}{*}{ ALUNO } & \multicolumn{2}{c}{ NOTAS } \\
\cline { 2 - 3 } A1 & PRÉ-TESTE & PÓS-TESTE \\
\hline A2 & 7,5 & 6,25 \\
\hline A3 & 6,25 & 7,5 \\
\hline A4 & 6,25 & 7,5 \\
\hline A5 & 6,25 & 8,75 \\
\hline A6 & 6,25 & 8,75 \\
\hline A7 & 6,25 & 8,75 \\
\hline A8 & 5 & 7,5 \\
\hline A9 & 5 & 6,25 \\
\hline A10 & 5 & 6,25 \\
\hline A11 & 5 & 6,25 \\
\hline A12 & 2,5 & 5 \\
\hline A13 & 2,5 & 3,75 \\
\hline A14 & 2,5 & 2,5 \\
\hline A15 & 1,25 & 1,25 \\
\hline A16 & 1,25 & 1,25 \\
\hline A17 & 1,25 & 2,5 \\
\hline A18 & 1,25 & 2,5 \\
\hline A19 & 1,25 & N/D \\
\hline A20 & 1,25 & \multicolumn{2}{c}{} \\
\hline & 515 \\
\hline
\end{tabular}

Fonte: adaptado de CUNHA (2014)

\section{Verificação dos pressupostos de normalidade e homocedasticidade}

a) Teste de normalidade da variável "pré-teste"

Teste utilizado: teste de normalidade de ShapiroWilk, uma vez que existem menos de 50 observações.

- H0: os dados seguem a distribuição normal;

- H1: os dados não seguem a distribuição normal.

Observa-se que ovalor de $p$ émaior que 0,100 (Figura 4). Como este valor é maior que o nível de significância estabelecido de $5 \%(0,05)$, não há indícios para a rejeição da hipótese nula, e pode-se dizer que os rendimentos dos voluntários seguem a distribuição normal.

a) Teste de normalidade da variável "pós-teste"

Teste utilizado: teste de normalidade de ShapiroWilk, uma vez que existem menos de 50 observações.

- H0: os dados seguem a distribuição normal; 


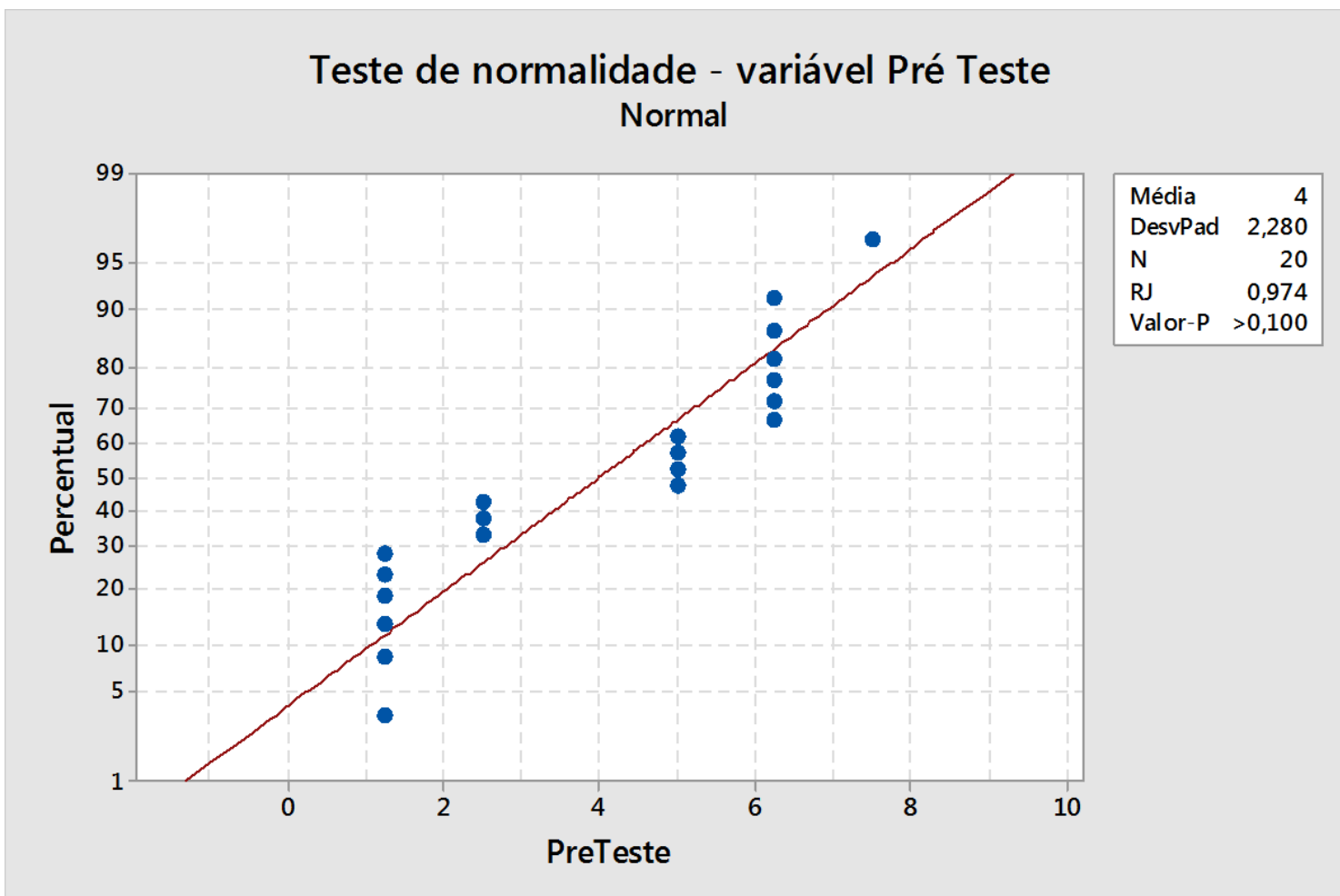

Figura 4. Gráfico da análise da normalidade do rendimento dos voluntários no pré-teste. Fonte: CUNHA (2014).

• H1: os dados não seguem a distribuição normal.

Observa-se que o valor de p é maior que 0,100 (Figura 5). Como este valor é maior que o nível de significância de $5 \%(0,05)$, não há indícios para a rejeição da hipótese nula, e pode-se dizer que os rendimentos dos voluntários que utilizaram a ferramenta computacional, seguem a distribuição normal.

b) Verificação da homocedasticidade

Teste utilizado: teste de homocedasticidade de Levene.

- H0: os dados são homocedásticos;

• H1: os dados não são homocedásticos.

A Figura 6 apresenta o resultado do teste de homocedasticidade com o valor de $p$ igual a 0,663, maior que o nível de significância estabelecido de 0,05 (5\%). Desta forma, pode-se afirmar que os dados são homocedásticos (igualdade de variâncias).

\section{c) Escolha do teste estatístico}

Os dados são organizados em duas amostras dependentes, já que um mesmo aluno participou dos dois grupos. Os dois últimos valores, referentes aos alunos A19 e A20, precisaram ser descartados, pois, estes participaram apenas do pré-teste.

Os dados são quantitativos, seguem a distribuição normal, a variância populacional é desconhecida, e sabese que a variância dos dois grupos é igual. Portanto, pode-se utilizar um teste paramétrico para a comparação das médias.

Satisfeito o pressuposto de normalidade e homocedasticidade, pode-se proceder com a análise de comparação das médias das duas amostras, gerando um novo teste de hipóteses, a um nível de significância de $5 \%$. Pode-se utilizar o teste T de Student pareado para comparar médias de duas amostras dependentes.

\section{Comparação das médias}

Teste utilizado: teste T de Student pareado.

- H0: as notas dos voluntários antes do uso da ferramenta são iguais às notas dos voluntários após a utilização da ferramenta.

- H1: as notas dos voluntários antes do uso da ferramenta não são iguais às notas dos voluntários após a utilização da ferramenta.

Observa-se que o valor de pé igual a 0,002 (Tabela 2). Como este valor é menor que o nível de significância de $5 \%(0,05)$, então, não há indícios para aceitar a hipótese nula de que os dados são iguais, aceitando-se a hipótese alternativa de que as médias são diferentes, ou seja, uma melhor do que a outra.

Observa-se que a média anterior à utilização da ferramenta foi de 4,306 pontos, enquanto a média após a utilização do portal educacional apresentou melhora e foi de 5,278 pontos, o que pode ser confirmado no 


\section{Teste de normalidade - variável Pós Teste Normal}
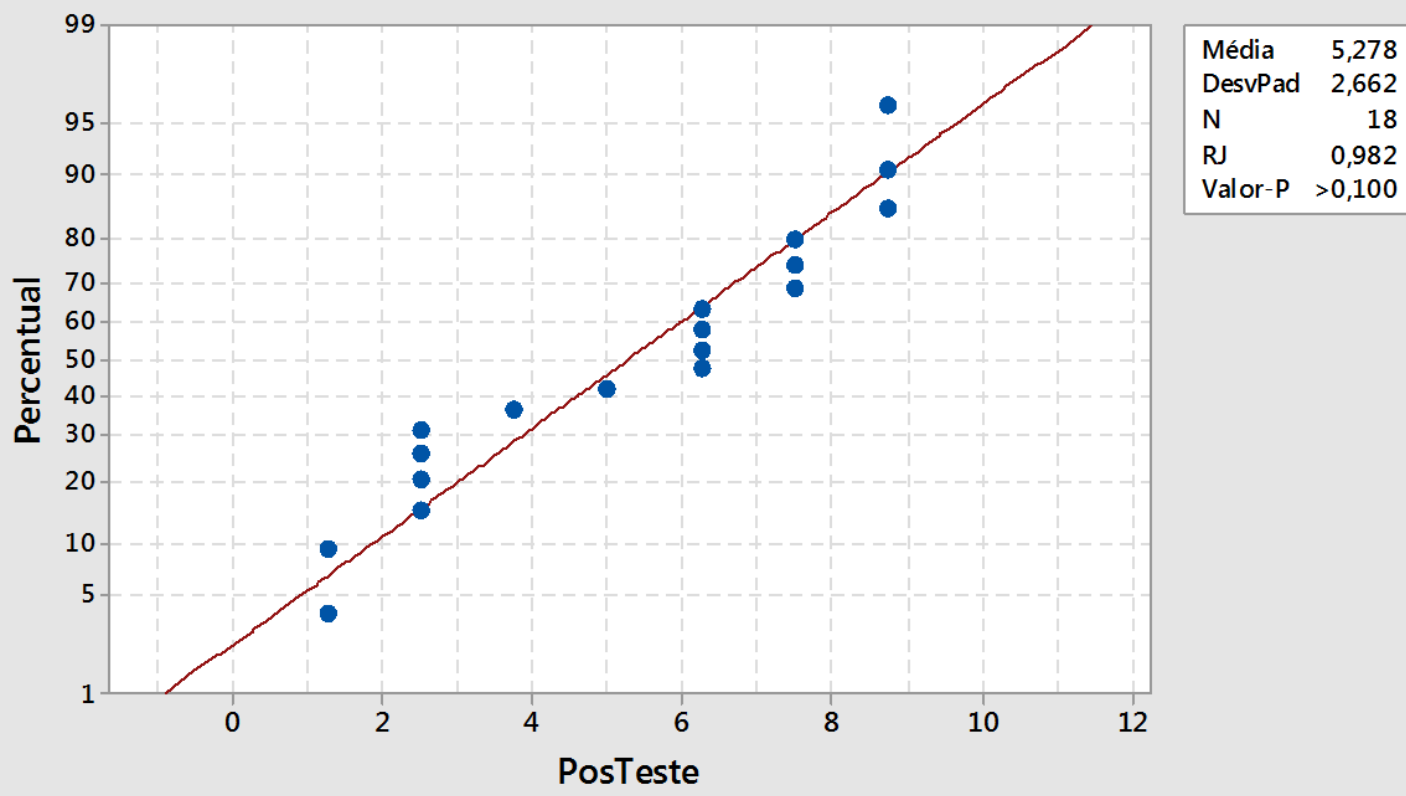

Figura 5. Gráfico da análise da normalidade do rendimento dos voluntários no pós-teste. Fonte: CUNHA (2014)

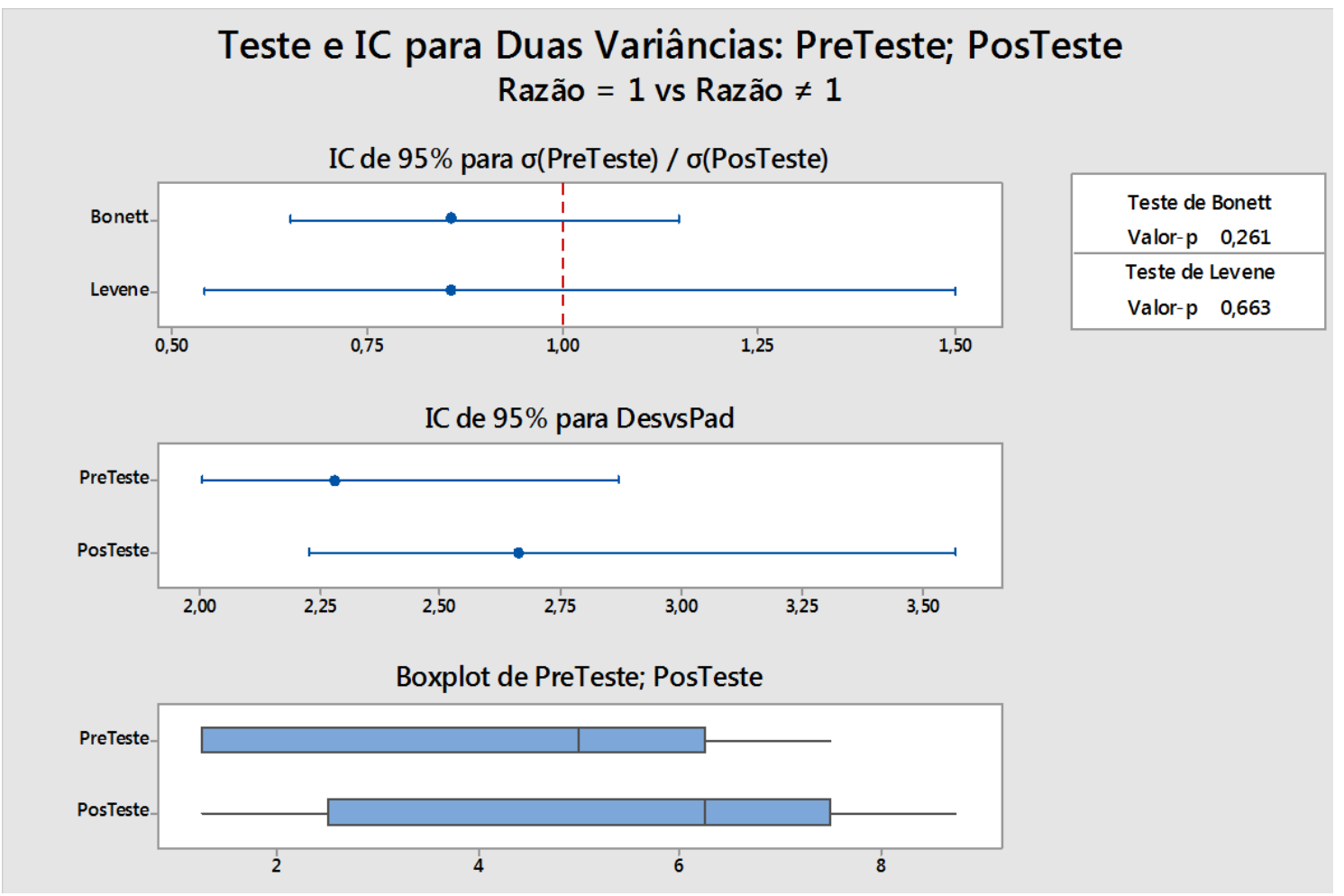

Figura 6. Gráfico do teste para duas variâncias.

Fonte: CUNHA (2014).

gráfico Boxplot da Figura 7.

Mediante o resultado apresentado, podese concluir que na primeira execução do estudo experimental, a avaliação demonstrou que a ferramenta influenciou positivamente na aprendizagem dos participantes deste estudo. Entretanto, é importante que este estudo experimental seja repetido a fim de assegurar a importância do projeto no processo de ensino e aprendizagem.

Diante do estudo experimental realizado e dos dados estatísticos obtidos mediante análise, podese observar que a Ferramenta de Regra de Três 
Tabela 2. Teste T de Student pareado e IC: pré-teste; pós-teste.

\begin{tabular}{ccccc}
\hline & N & Média & Desvio Padrão & EP Média \\
\hline Pré-Teste & 18 & 4,306 & 2,196 & 0,517 \\
Pós-Teste & 18 & 5,278 & 2,662 & 0,627 \\
Diferença & 18 & $-0,972$ & 1,098 & 0,259 \\
\hline Fonte: CUNHA (2014). & & &
\end{tabular}

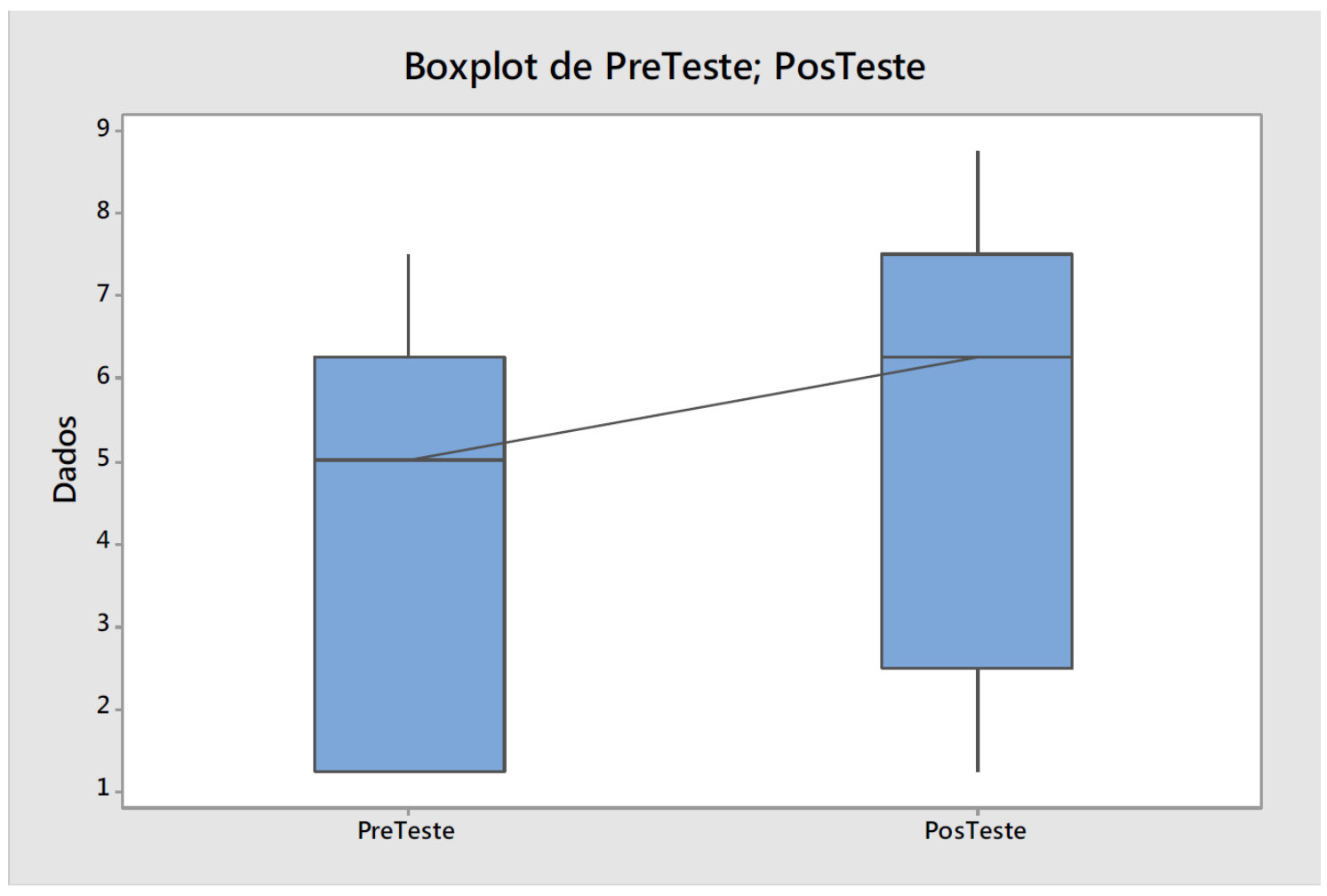

Figura 7. Gráfico Boxplot do pré-teste e pós-teste. Fonte: CUNHA (2014).

influenciou, positivamente, no entendimento do tema abordado por este trabalho.

Visto isto, vale ressaltar que, como houve apenas um estudo experimental e este foi aplicado em ambiente de estudos, não há possibilidade de se afirmar que a ferramenta atingiu completamente seu objetivo. Há a necessidade de mais estudos serem realizados e, se possível, que os dados coletados sejam provenientes de casos reais. Estes deverão ser analisados novamente para averiguar qual a influência do uso da ferramenta. Deste modo, evidências mais concretas poderão reiterar a eficácia da ferramenta.

\section{Considerações Finais}

O objetivo deste trabalho foi desenvolver uma ferramenta para o auxílio do ensino e aprendizagem da Regra de Três para profissionais da área de Saúde. Este trabalho partiu da constatação das dificuldades que alguns estudantes e profissionais da Saúde têm ao realizar operações matemáticas básicas envolvidas na administração ou prescrição de medicamentos.
A eficácia da ferramenta foi constatada mediante a aplicação de um instrumento de avaliação anterior e posteriormente à sua utilização e análise estatística dos dados adquiridos.

A importância desta ferramenta reside na possibilidade de enfrentar com êxito a alta taxa de eventos adversos provenientes de erros de cálculo de dosagens, diluição e gotejamento de medicamentos que poderiam ter sido evitados. A fim de lidar com esta dificuldade, esta ferramenta foi desenvolvida e hospedada na Web.

$\mathrm{O}$ estudo experimental com a ferramenta logrou êxito quanto aos objetivos propostos e confirmou a hipótese ensejada de que a construção e disponibilização de uma ferramenta de apoio ao ensino ou aprendizagem da Regra de Três pode contribuir para a diminuição dos efeitos provenientes dos erros de cálculo de dosagens, diluição e gotejamento de medicamentos.

Vale ressaltar que, uma vez concluída esta etapa, há a necessidade de novos estudos para que haja o acompanhamento e avaliação dos resultados futuros que a ferramenta poderá trazer ao ser disponibilizada a um número maior de usuários, sobretudo, no que diz 
respeito ao diálogo aberto com as formas tradicionais de ensino e aprendizagem do cálculo de dosagens, diluição e gotejamento de medicamentos.

\section{Referências}

Carvalho, V. T.; Cassiani, S. H. B (2002). Erros na medicação e consequências para profissionais de enfermagem e clientes: um estudo exploratório. Revista Latino-Americana de Enfermagem, 10(4), 523-9.

Carvalho, V. T.; Cassiani, S. H. B.; Chiericato, C (1999). Erros mais comuns e fatores de risco na administração de medicamentos em unidades básicas de saúde. Revista Latino-Americana de Enfermagem, 7(5), 67-75.

Cunha, A. S (2014). Matemática aplicada à enfermagem: apoio ao ensino do cálculo de dosagem e diluição de medicamentos através de um portal educacional. Dissertação (Mestrado Profissional em Educação Matemática) - Universidade Severino Sombra, Vassouras - RJ.

Dantas, R (2011). NetBeans IDE 7 Cookbook. Packt Publishing Ltd.

Deitel, H. M.; Deitel, P. J (2010). Java: Como Programar (8aed.). Prentice Hall.

Fiorentini, D (1995). Alguns modos de ver e conceber o ensino da matemática no Brasil. Zetetiké, Campinas, 3(4), 1-38.

Franklin, J (2013). Beginning jQuery. Apress.

Geary, D. M.; Horstmann, C. S (2010). Core JavaServer Faces (3a ed.). Prentice Hall.

Klug, D.; Ramos, M. G (2013). Saberes de Matemática utilizados por técnicos de enfermagem em sua prática profissional. Revemat: revista eletrônica de educação matemática, 8(1), 119-37.

Silveira, M. R. A (2000). A interpretação da Matemática na escola, no dizer dos alunos: ressonâncias do sentido de "dificuldade". Revista Liberato, $1(1)$.

Valente, J. A. (2008). Diferentes usos do computador na educação. Inep, 12(57).

Varaksin, O (2013). PrimeFaces Cookbook. Packt Publishing Ltd. 